\title{
John R. Martin
}

\section{Round Table on \\ 'Free and Frank Advice' Summary of Discussion}

The round table at which Professor Mulgan presented

his paper was attended by over 40 participants, including

past and present ministers, chief executives and senior

managers, academics, independent researchers, observers

and commentators. The discussion was conducted under the

Chatham House Rule. The following is a summary record.

Professor Jonathan Boston (Institute for Governance and Policy Studies) and Len Cook (president of IPANZ) opened the round table. Cook noted that 2012 was the centenary of the Public Service Act and that 'free and frank advice' was central to the ethos that was the legacy of that statute. Boston, as chairman, invited Emeritus Professor Richard Mulgan (Crawford School of Public Policy, Australian National University, Canberra) to introduce the discussion.

Setting the scene

Professor Mulgan said that 'free and frank advice' ('frank and fearless' in Australia)

John R. Martin was a public servant for over 30 years and then taught public administration at Victoria University of Wellington for over a decade. was a time-honoured catchphrase about which generalisation was difficult. Hard evidence was lacking and enquiry was largely based on anecdote. Experience varied across jurisdictions and he registered the caveat that he was not as upto-date about New Zealand as he would wish to be. In these introductory remarks he would explore the meaning of 'free and frank advice', discuss some current challenges, and reflect on possible lessons for the future.

'Free and frank advice' was a hallowed tradition under which officials are obliged to speak their minds openly and honestly and to tell ministers things that they may not wish to hear. But 'free and frank' is not the only feature of public service advice. Values such as impartiality and integrity - which underpin New Zealand's reputation as being quite corruptionfree - are also significant. Advice from officials is expected to be 'scrupulously accurate' and to be balanced and unbiased in its assessment of evidence. These are also 'academic values'. Professor Mulgan underlined in his presentation that he considered the New Zealand public service had retained elements of free and frank advice that had been lost elsewhere.

'Free and frank advice' is not a property only of the public service; others in positions of authority also expect their advisers to speak their minds freely. And ministers expect 'free and frank advice' from private advisers and community members. But officials operate within a distinctive framework in which the government makes the final decisions. Ministers depend, however, on the reliability of the advice of officials - on its factual accuracy and balanced judgement. Respect for truth and evidence is the key.

The policy function has been neglected in recent years, by comparison with concerns about public sector management. Recent reports by Scott in New Zealand and Moran in Australia (Review of Expenditure on Policy Advice, 
2010; Advisory Group on Reform of Australian Government Administration, 2010) have pointed to systemic weaknesses in policy advice, especially in relation to strategic long-term advice. One consideration in recent years affecting the standing of public service advice is that officials have not 'had the ear' of ministers to the extent that they have had previously. The increasing numbers of advisers in the ministers' offices has been one contributing factor. Another has been the changing media cycle. The ' 24 hour news cycle' requires a commitment of time from ministers, increased reliance arena, and may be seen to differ from the policy determined by the minister. Postelection briefings are an example.

The degree of openness now in place marks a significant change in the model of policy advice. The traditional model was a closed, tightly-controlled process in which ministers and departments presented a united front: public servants were 'the insiders'. The new model is 'pluralistic': public servants compete in an open marketplace of ideas with no assurance that their advice will be accepted. This requires a 'meta-advice' function, 'advice on advice': who assists

\section{A major challenge to the public service is to provide quality policy advice by leveraging the various sources of credible options available to ministers.}

on media and tactical advisers, and less time for longer-term policy issues.

The public service does not have a monopoly on policy advice. Over recent decades ministers have made increasing use of external sources of advice: consultants, think tanks and interest groups. Public service advice is only one among several sources.

'Evidence-based' policy is in favour. The notion that policy can be a matter for political compromise among interests has less support and the language of research-based evidence is pervasive. One consequence is the strengthening of interest groups' capacity - in-house experts and use of think tanks and consultants - to muster their own evidence-based arguments to promote their policy stances. What purports to be evidence-based policy can, however, be policy-based evidence. Options based on such selective evidence compete with the department's advice.

Greater transparency promoted by the Official Information Act 1982 (the Freedom of Information Act 1982 in Australia) also emphasises that public service advice is only 'one among many'. The written advice of departments is likely to become available in the public the minister to choose from among the range of views advanced? Public servants, as trusted advisers loyal to the government, have the experience and information to play this role. There is a strong case for confidentiality in respect of 'free and frank' advice of this kind. Indeed, a distinction can drawn between (a) policy research and analysis by departments or external providers, where the pluralistic, open model is appropriate; and (b) advice considering policy options and making recommendations.

This situation requires a revisiting of the official information legislation. In the adversarial Westminster system there is a strong case for confidentiality in respect of politically sensitive meta-advice. This is a contentious issue. In Australia, recent statutory changes have ruled out political embarrassment for the government as an acceptable reason for withholding disclosure of documents. On the other hand, United Kingdom legislation enables the withholding of 'free and frank exchange of views for the purposes of deliberation' (Freedom of Information Act 2000, s36 2(b)). The question is 'where to draw the line'. There is a need to balance the competing principles of, on the one hand, transparency and openness, and on the other the essential maintenance of trust between ministers and officials.

There may be advantage in distinguishing between the department as a collective unit and the senior management. Unlike meta-advice, data and policy research produced by the department does not necessarily carry the imprimatur of the chief executive or senior management (or the minister) and should be in the public arena. That is part of the wider public debate, along with the work of arm's-length organisations such as the Productivity Commission, who are also expected to speak 'without fear or favour'. (And, like other markets, the marketplace of ideas cannot be effectively planned.)

\section{No 'golden age'}

Discussion on Professor Mulgan's remarks began with a caution that there was no 'golden age' of policy advice, and that, relative to the size of the public service as a whole, the policy advice function, while clearly important, is not overwhelming in the day-to-day work of the public service. The drivers of change now are different from 30 years ago. Issues are much more complex: solutions cannot 'be pulled off the shelf'. Policies aiming to change the behaviour of citizens need to take into account the differing capabilities and interests in the community. The public service has to be more open.

A major challenge to the public service is to provide quality policy advice by leveraging the various sources of credible options available to ministers. The Land and Water Forum ${ }^{1}$ is an example of collaboration of interests in the policy process. It reflects the decreasing willingness of the community to accept 'tablets of stone' handed down by the government of the day. There is also a requirement to work across ministerial portfolio areas and to provide policy advice for the longer term.

The official information setting is an important factor in the context in which policy advice is provided. It helps to shape the culture of a more transparent public service. But it also provides the basic material in the 'war of attrition' between the government of the day and 
the opposition, which has a slow but corrosive effect on the policy process. The focus tends to be on the provision of advice in the short term, with less priority for medium- and long-term issues. The public service has to adapt to the world as it is and to embrace experimentation.

'Free and frank advice' requires a high degree of trust between ministers and officials. Public servants have a privileged position; in return, they are expected to provide the advice ministers want. But the place of the public service is much less 'monastic' than in the traditional model. It has to see itself as much more outward-looking.

The imminent report of the Law Commission on the Official Information Act (OIA) would promote a conversation about practice in understanding of the processes of government, but the option of greater confidentiality is not open. The rules of engagement require the routine proactive release of information about ministerial decision making - but also a greater understanding on the part of those making requests.

Amendments to the State Sector Act 1988 would be introduced shortly. One purpose would be to elaborate on the functions of chief executives beyond the requirement of the principal act, i.e. simply to tender advice. The chief executive has an obligation to ensure that the department has the capacity to deliver quality advice.

\section{Evidence-based policy or policy-based} evidence?

The impact of the media on the quality of free and frank advice was emphasised. The current Leveson enquiry in the United Kingdom has implications for New Zealand. Rational reasoning is central to policy making, but activists and even academics seek evidence to back their views. How do ministers and officials safeguard the quality of evidence on which decisions are made?

The OIA has had a 'chilling effect' on free and frank advice. A massive bureaucracy is needed to administer the OIA. The genie could not be put back in the bottle but there is a need for greater clarity about what constitutes 'official information'.
The relevance of the OIA to Parliament was raised. There would be strong opposition to any move to apply the Act to Parliament. Parliament is not part of executive government, and the application of the Official Information Act would bring it under rules specifically developed to oversee and monitor the executive. More important is the need for ministers and departments to strengthen their relationship in responding to parliamentary questions. Too often ministers are not provided with adequate information to respond adequately.

The OIA as an incentive for quality advice

The positive effect of the OIA in 'driving out bad advice' was acknowledged. The the advice stage with informal 'green fields' discussions.

Attention was drawn to the different approaches of New Zealand and Australian official information legislation. Australia's legislation is prescrip-tive, leading to more games being played. The New Zealand act is 'principle-based', with the trade-off between the presumption of availability and reasons for withholding acknowledged in the act. It was later noted that the New Zealand review procedure is simple - a request to the ombudsman but one consequence is that there is not an extensive jurisprudence about the meaning of the act to guide the public. The ombudsman's approach is, as with maladministration, to deal with the

\section{[T]he 'logjam' of OIA requests could be unblocked by a decision in principle to release all Cabinet decisions on a website after, say, two months ...}

duty of officials is to provide 'factual and balanced' advice that will stand up to public scrutiny. Sensitive political advice is adequately protected by the legislation (subject to the ombudsman's agreement). Another participant urged caution in withholding information or 'blacking out' material: this results in further requests to the ombudsman. There could be greater clarity about what constitutes 'information'; the importance of 'due particularity' was emphasised.

It was suggested that the 'logjam' of OIA requests could be unblocked by a decision in principle to release all Cabinet decisions on a website after, say, two months - there would be a presumption of release. 'Fishing expeditions', often by the media, contribute to the logjam, but a case was made for their legitimacy as an instrument available to the opposition. Experience also suggests that the management of release, including timing, is relevant to the media interest in pursuing further inquiries.

Another way of reducing OIA pressures on the policy advice process is for ministers or their advisers to precede case. The Law Commission's report may provide guidance and, it was suggested, there is a case for the executive (the State Services Commission?) to encourage the learning process. (Reference was made to the Information Authority set up under the OIA, but it has been disbanded.)

There seemed to be a consensus around the premise that the OIA could not be rolled back. But how had it affected free and frank advice? Had it encouraged oral advice? Had there been, as earlier suggested, a 'chilling' impact on policy advice?

One response was that there has been no effect. The ambit of the act extends beyond written advice to information 'in the head'. Another was that the onus is on the adviser to present balanced advice - 'the pluses and minuses' - on the assumption that it would be protected until it was appropriate to release. In response to the question as to whether the crucial factor was the relationship with the minister or the integrity of the public servant, the capacity of experienced practitioners was underlined. The point was made that oral advice lacks the 
discipline of written advice, and it was noted that the style of written advice has changed in some respects: emphasis is given to the presentation of options. There is also experience of advice being rewritten to align with the decision already made.

One aspect of the relationship between free and frank advice and the OIA is the treatment of injudicious comments (often by email) between officials and across departments. Illconsidered, flippant emails carry risks. The way in which the act affects staff varied. Some are too cautious; others too provision of key policy material. Do departments require ministerial approval to release reports? Free and frank advice is about content not process.

Discussion returned to the costs of administering the OIA, and a strong plea was made to move to the automatic release of information, thus reducing the room for discretion.

Rounding off the consideration of the OIA's impact on free and frank advice, the point was made that a strength of the New Zealand system lies in its informal nature. Crucial to the provision of quality policy advice is the element

\section{A salutary message to policy advisers is to 'avoid folly' - to seek to avoid unintended consequences and to advise on the prospect of policy succeeding in achieving the desired outcomes.}

casual. The importance of oral briefings on sensitive topics was emphasised. And the value of informal group meetings, already mentioned, in which the minister is a participant was endorsed.

\section{Proactive advice}

Proactive advice to ministers by departments can present difficulties. The process of policy-making is changing. The new emphasis on results will require change. There is a need for a more dynamic process involving advice from many sources. But, it was stressed, it is the decision that matters.

The significance of the context provided by seven-day, 24-hour media attention was again emphasised. It is not only data that is in the public arena that matters; it is the interpretation of that data that has an impact. There is always a risk of 'yes/no' conclusions being drawn from complex material.

Post-election briefings are an important vehicle of proactive advice. One view was that they had in recent years become 'seriously diluted' and could be construed as 'political documents'. The Treasury's statutory obligations under the fiscal responsibility provisions of the Public Finance Act exemplify the public of trust among those involved - a point repeated throughout the discussion - and trust requires a confidential relationship between ministers and officials. There is a case for underlining this in the OIA (after all, the courts do not expose all their drafts).

\section{The short and long term}

A frequently-expressed concern about the advice process is ministers' preoccupation with the short term and a consequent lack of priority for the medium and long terms. How can this tension be reconciled?

A strong view was expressed in support of greater involvement of the community in policy making. This went beyond the standard consultation: citizens want 'in'. This requires a reduction in the 'privilege of the executive' in respect of both research and policy advice. It was observed that some necessary research does not proceed because the 'minister was not interested'. Officials find ways of other sources of advice getting to ministers. Technological change is relevant to greater community involvement.

It was observed that 'the truth was hard to find'. Policy advice usually requires a trade-off. The meta-policy role earlier discussed is the key. But the point was later made that officials have an obligation to provide free and frank advice about how ministers exercise their discretion in choosing among different streams of advice.

An important distinction was made. Research should be value-free; policy advice brings values into play. Independence in research is essential. It should also be acknowledged that there are gaps in knowledge and that the effects of policy options are uncertain. It is necessary to identify what we don't know. The notion of risk is central; but there are different meanings of risk: mathematical risk, political risk. The underpinning of policy by evidence is basic.

Ministers are sometimes confronted with ongoing policy research from departments that is outside the ambit of the government of the day. Where is the boundary between work commissioned by the minister and inherited projects? One response was that as long as major resources are not involved, departments should continue with such work.

One interpretation of the role played by the department in considering various streams of advice - meta-advice - is that it should appear to be disinterested: it is a broker rather than a monopoly. A risk in this stance is that the department risks losing depth in its own capacity. It is necessary for the department to have contact with the other sources of advice. Another relevant factor is the place of ministerial advisers. Given the 'media pressure for rapid response', private offices could 'get in the way'.

Free and frank advice is an art requiring a high degree of sophistication. Time and effort had to be devoted to building relationships. The key elements are trust, confidence and respect.

The environment in which governments operate now moves so fast that strategic thinking about the medium and long terms could get lost in the system (but the example of such countries as Norway with comprehensive economic planning was mentioned).

Several points about research were highlighted. Research covers a 'multitude of activities': they need to be unbundled. The importance of quality evaluation was stressed. This is 'research looking 
backwards'. Too many RFPs (requests for proposal) for evaluation are a waste of time because of initial bad design. Research and development is about informing public policy, not advising.

Experience shows that too often policy is blamed for inadequate outcomes. In fact, the weaknesses may lie elsewhere: for example, in implementation or structures.

\section{The public service's stewardship role}

The public service has responsibility for the stewardship of the public policy process. It is not an 'independent actor', but chief executives may 'judiciously' lead public debate on long-term issues, such as the age of entitlement for New Zealand Superannuation.

A view was strongly expressed that the traditional model of the policy process is out of date. Policy advice still looks 'monopolistic'. The public service has the capacity to 'narrow down' the public debate. Recognition should be given to the contribution of Crown entities charged with advising on medium- and long-term issues (e.g., the retirement commissioner, the Productivity Commission). Others, such as ACC, interact with citizens whose voice is too often 'choked off'. The model needs attention.

'Balanced, fair and factual' is a more accurate representation of quality policy advice than 'free and frank'.

The relationship between ministers and chief executives was again raised as a central issue.

A respected administrative leader is not necessarily a trusted policy adviser. Is the 'partnership' description still accurate? The place of ministerial advisers was again mentioned. It is their job to manage the public service in the interests of the government. Chief executives have an obligation to manage the policy process within departments. This implies the need for a close relationship with the chief ministerial adviser, not only with the minister.

The pluralism of sources was also returned to and the claim made that departments have not sufficiently adapted. As an example, too many officials do not understand how business works: for example, about the importance of time frames in such areas as disclosure to the stock exchange. Another area requiring attention is the provision of advice to Parliament.

The public service - and the policy process - have an obligation to look to the long term, for instance in acknowledging the future needs of the young people of today. Where advice is 'written to order' it risks leading to 'evidence-free' papers. Where there is a void in the knowledge, officials tend to play safe.

Reference was made to a claimed 'heroic age' in the place of official advisers. The case of Minister of Justice Ralph Hanan and Secretary of Justice John Robson in the 1960 s was mentioned, as was the writing of Robert Parker (Parker, 1993). ${ }^{2}$ As Allen Schick pointed out in 1996, it is crucial to get right the relationship between ownership and purchase (Schick, 1996).

Experience showed that the ability to provide successive ministers with quality advice is founded on the long-term work of the department. An example was cited of rebuilding departmental capacity so that it could take a 99-year view. The platform on which policy advice is delivered is also important. The example of the Land and Water Forum was again commended. The parties called in to participate in policy-making respect the process.

A salutary message to policy advisers is to 'avoid folly' - to seek to avoid unintended consequences and to advise on the prospect of policy succeeding in achieving the desired outcomes. Ministers need to be able to judge the reliability of the knowledge on which departmental advice is based, and officials should be able to express an opinion about the choices before ministers. There is a professional vocation of policy advice. (And the point was made that ministers can advise too: 'free and frank advice works both ways.) The timing and presentation of policy advice is also crucial.

\section{Conclusion}

There was a general conclusion that the discussion had been worthwhile. There was room to develop further the issues that were raised. The publication of the Law Commission's report on the Official Information Act 1982 and the awaited tabling of amendments to the State Sector Act 1988 could provide opportunities to resume the discussion.

\footnotetext{
1 http://www.landandwater.org.nz.

2 Robert Parker taught at Victoria University and at the Australian National University, and was a leading figure in the New Zealand Institute of Public Administration in the 1940 s and 1950s.
}

\section{References}

Advisory Group on Reform of Australian Government Administration (2010) Ahead of the Game: blueprint for the reform of Australian government administration, http://www.dpmc.gov.au/publications/ aga_reform/aga_reform_blueprint/docs/APS_reform_blueprint.pdf

Parker, R. (1993) The Administrative Vocation, Sydney: Hale and Ironmonger
Review of Expenditure on Policy Advice (2010) Improving the Quality and Value of Policy Advice, http://www.treasury.govt.nz/statesector/ policyexpenditurereview

Schick, A. (1996) The Spirit of Reform: managing the New Zealand state sector in a time of change, Wellington: State Services Commission 